\title{
A Simulation Method Focused on Electric-Heating Distillation of Ethanol in Solid-State Fermented Crushed Straw Material
}

\author{
Jingzhi Zhou ${ }^{1}$, Junxiao Feng ${ }^{1,3,}$, Zhixing Zhou ${ }^{2}$ and Shizhong $\mathrm{Li}^{2}$ \\ ${ }^{1}$ School of Energy and Environmental Engineering, University of Science and Technology Beijing, Beijing 100083, China \\ ${ }^{2}$ Institute of Nuclear and New Energy Technology, Tsinghua University, Beijing 100084, China \\ ${ }^{3}$ Beijing Key Laboratory for Energy Conservation and Emission Reduction in Metallurgical industry, Beijing, China
}

${ }^{*}$ Corresponding author

\begin{abstract}
In order to build the simulation method based on DEM, test orthogonal test and complete test was done. Based on electric heating test, the ethanol distillation mechanism of solid-state fermented crushed straw material was studied. The main factors influence the distillation speed are wet content, heating temperature, ethanol concentration in the wet. The results show that the last factor's impact can be ignored. Distillation speed linearly increase with more wet content, increase as power function with higher temperature. Based on mathematical model regressed and discrete element method, a set of simulation method was build which can be used to simulate the electricheating distilling process of solid-state fermented crushed straw material. There is no such distillation simulation method based on DEM before.
\end{abstract}

Keywords- DEM; API; solid-state fermentation

\section{INTRODUCTION}

Every year, nearly 1 billion tons of straw was harvested in China, which amount to 0.5 billion tons of standard coal ${ }^{[1]}$. Most of them is burned which increase air pollution. Professor Shizhong LI firstly use rotary drum to continuously solid-state ferment crushed straw material to produce ethanol. The technology is pollution-free and cheap, and has been put into industrial production which results in excellent economic and environmental benefit ${ }^{[2]-[3]}$

The highest energy consumption $(60 \% \sim 70 \%)$ comes from separation process. The current method to separate ethanol from fermented material is to lay the material in a streamer, continually inlet hot vapor through the material and take away the ethanol molecules. The vapor gathers at the top of streamer and flows to fractionation tower to distillate ethanol. However, the current separation process has many disadvantages: (1) material leakage, (2) introduce a large amount of water which increase the cost of fractionation, (3) hot vapor cannot take all the ethanol molecule and there is still ethanol residue in material, (4) large equipment, (5) discontinuous production, (6) more human demand. ${ }^{[4]-[6]}$ In order to solve these problems, electric-heating distilling was considered to separate ethanol instead of vapor.

The distillation mechanism of ethanol need to be studied first. Small volume material was considered as the research object, then all the material can be considered as a group of large amount of small volume material and the small volume material is the unit of material bed. When the distillation mechanism of small volume material was got, a simulation method to simulate distillation process could be built based on Discrete Element Method (DEM) software EDEM and API.

\section{Distillation MECHANISM OF ETHANOL IN FERMENTED MATERIAL}

\section{A. Existing Form of Wet in Fermented Material}

Some fermented material was completely dried and evenly added with ethanol solution, which are the prepared material. The prepared material's density, wet content and ethanol concentration in wet were equal to the fermented material. Comparing the distilling process of fermented material with prepared material. The prepared material is the control group and the fermented material is the experimental group. Electric heating the two groups with the same temperature, record the weight per minute and draw weight - time curve. If the difference between the two curves is small, the existing form of ethanol in prepared material can be equivalently thought the same as in fermented material, and prepared material can be used to quantitatively study the distillation mechanism of fermented material. The dried fermented material is porous media and it will absorb added solution into the tracheid and dried cells. As all the cells are die, the added solution will not be compounded with dried material ${ }^{[7]}$.

Test equipment: Moisture analyzer (Sartorius MA150) ${ }^{[8]}$. Software to automatically record weight date: Wedge 1.1 .

Test procedures:

(1) Some samples of fermented material was taken to measure the average value of wet content and ethanol concentration in wet. The result was $0.8,7 \%$. $20 \mathrm{~g}$ sample of fermented material was taken and divided into two equal parts. One was put into a preservation bag and the other was completely dried (obviously, the dried material's weight is $2 \mathrm{~g}$ ). The dried material was put into another preservation bag and added with $8 \mathrm{~g}$ ethanol solution of $7 \%$. The bag was putted in shade until there was no liquid in it, which means that the solution has been completely absorbed by dried material. It 
generally takes about 1 day. The volume of the two group are the same because the volume of material is determined by the volume of dried material in it. The fermented material is the experience group. The prepared material is the control group.

(2) The temperature of heating disc in Moisture Analyzer was set $100^{\circ} \mathrm{C}$. The fermented material in preservation was laid on disc. The weight data was automatically recorded until the material was totally dried.

(3) The same operation was done on prepared material. The weight-time curves of the experimental group and the control group were drawn in Figure 1.

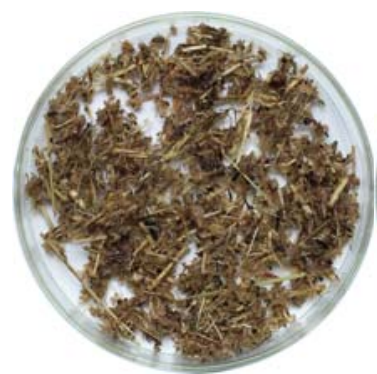

(a)

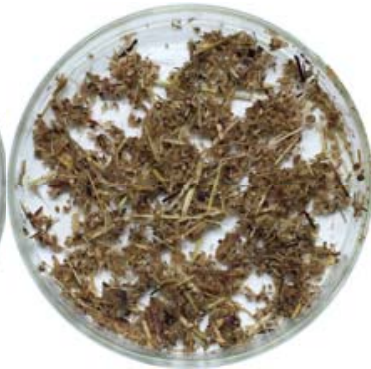

(b)

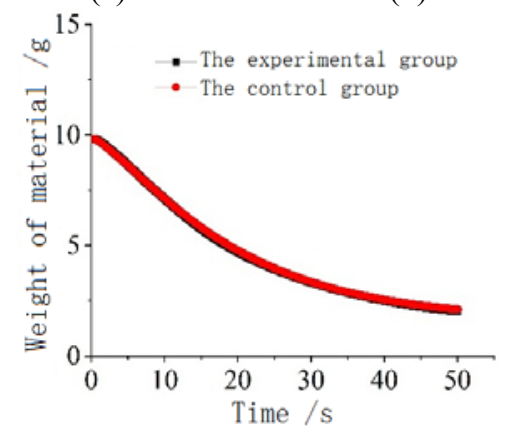

FIGURE I. FERMENTED MATERIAL, PREPARED MATERIAL, AND THE RESULT OF TEST (A-FERMENTED MATERIAL BPREPARED MATERIAL)

As shown in figure 1 , the difference between curves is very small, the relative error is less than $3 \%$. Thus the existing form of wet in fermented material can be equivalently considered as the same in prepared material, and the prepared material can be used to quantitatively study the distillation mechanism of fermented crushed straw material under electric heating.

\section{B. Distillation Mechanism of Ethanol in Ethanol Solution}

As the added solution does not compound with dried material, the electric-heating distilling process of material can be considered as electric-heating distilling process of ethanol solution on straw shaped heating device. The distillation mechanism of ethanol solution need to be studied. The equations describing the distillation process of ethanol from ethanol solution was derived based on data from reference ${ }^{[9]}$. Hypothesis: the stream is rapidly moved away and the distilling speed will not be influenced by gas saturation.

$$
\omega_{i+1}=\frac{\omega_{i} \cdot m_{i}-d n \cdot\left(\omega_{i} \cdot K_{\omega \omega_{i}}\right)}{m n_{t}-d m} \times 100 \%
$$

$$
Q_{i}=P d \tau_{i}=E_{\left(\omega_{i} t_{i}\right)} \cdot d m+C_{\left(\omega \omega_{i} t_{i}\right)} \cdot\left(n \tau_{i}-d n\right) \cdot\left(t_{i+1}-t_{i}\right)
$$

$$
\begin{gathered}
K=183.58-237.78 \cdot \ln \left(\omega_{i}\right)-0.14 \cdot\left(\ln \left(\omega_{i}\right)^{2}\right. \\
+176.11 \cdot\left(\ln \left(\omega_{i}\right)\right)^{3}-139.06 \cdot\left(\ln \left(\omega_{i}\right)\right)^{4} \\
+51.6 \cdot\left(\ln \left(\omega_{i}\right)\right)^{5}-10.44 \cdot\left(\ln \left(\omega_{i}\right)\right)^{6} \\
+1.11 \cdot\left(\ln \left(\omega_{i}\right)\right)^{7}-0.05 \cdot\left(\ln \left(\omega_{i}\right)\right)^{8}
\end{gathered}
$$

$$
E=\left(\frac{-24.77+\omega_{i}}{-0.05+0.002 \cdot \omega_{i}}-3.25 \cdot \omega_{i}\right) \cdot \frac{1000}{4.187}
$$

$$
\begin{gathered}
C=\left(1049.5+6.9 \cdot \omega_{i}-6 \cdot t+0.03 \cdot \omega_{i}^{2}+0.035 \cdot t^{2}\right. \\
\left.-0.09 \cdot \omega_{i} \cdot t\right) /\left(4.187+0.035 \cdot \omega_{i}-0.026 \cdot t\right)
\end{gathered}
$$

$$
\begin{gathered}
t=100+64.44 \cdot \sqrt{\omega_{i}}-110.69 \cdot \omega_{i} \\
+79.69 \cdot \omega_{i}^{1.5}-32.5 \cdot \omega_{i}^{2}+8.25 \cdot \omega_{i}^{2}{ }^{2} \\
-1.36 \cdot \omega_{i}{ }^{3}+0.14 \cdot \omega_{i}{ }^{3}+5-0.01 \cdot \omega_{i}{ }^{4} \\
+0.00037 \cdot \omega_{i}^{4.5}-0.00000619 \cdot \omega_{i}{ }^{4}
\end{gathered}
$$

$$
m_{i} \geq K_{\omega x_{i}} \cdot d n
$$

$\omega_{\mathrm{i}}, \omega_{\mathrm{i}+1}$ - ethanol concentration in solution, percentage;

$\mathrm{Q}_{\mathrm{i}}$ - heat quantity the solution received, J;

$\mathrm{P}$ - heating power, equals to latent heat of vaporization per second, W;

$\mathrm{m}$ - mass of solution, $\mathrm{kg}$;

$\mathrm{dm}$ - mass change step of solution, $\mathrm{kg}$;

$\mathrm{d} \tau_{\mathrm{i}}$ - time change after a mass change step, s;

$\mathrm{K}$ - ethanol volatilization coefficient;

$\mathrm{E}$ - latent heat of vaporization of solution, $\mathrm{kcal} / \mathrm{kg}$;

$\mathrm{C}$ - specific heat capacity of solution, $\mathrm{kcal} /\left(\mathrm{kg} \cdot{ }^{\circ} \mathrm{C}\right)$;

$\mathrm{t}$ - temperature of solution, ${ }^{\circ} \mathrm{C}$.

Equation $\mathrm{K}, \mathrm{E}, \mathrm{C}$, $\mathrm{t}$ were regressed by data from references.

Set $\mathrm{dm}$ a small value, iterate $\omega_{\mathrm{i}}$ from $7 \%$ until $m_{i}<K_{\omega_{\mathrm{j}^{\prime}}} d m$. $\Sigma d \tau_{i}$ is the complete distillation time of ethanol. The smaller $\mathrm{dm}$ is, the more accurate $\Sigma d \tau_{i}$ is.

Calculating software was programmed by Visual Basic ${ }^{[10]}$. Set $\mathrm{dm}=0.0000000001 \mathrm{~g}$, mass of solution $=1000 \mathrm{~g}$, ethanol conversation $=7 \%$. The calculate result shows that the mass of solution was less than $4 \mathrm{~g}$ when $99.87 \%$ ethanol had been distilled, and there was still $2.28 \%$ ethanol in the $4 \mathrm{~g}$ solution. Heating temperature and heating power only influence the speed of distilling process, they didn't influence the distilling degree of ethanol. As a result, ethanol can only be totally distilled when solution was completely dried. The time solution totally dried is the time ethanol totally distilled. 


\section{Distillation Mechanism of Ethanol in Fermented Material}

Blank test result shows that the distillation speed of small volume material is impacted by heating temperature, wet content of material, ethanol concentration in wet.

In order to study the factors' importance order, orthogonal test was done. Commonly the wet content of fermented material is $0.7-0.8$, ethanol concentration in wet is $5 \%-7 \%$ [11]${ }^{[12]}$. The factors' levels were set wider than common situation.

TABLE I. ORTHOGONAL TEST AND RESULT

\begin{tabular}{|l|l|l|l|l|}
\hline No. & $\begin{array}{c}\text { Heating } \\
\text { temperature } \\
\text { / } \mathrm{C}\end{array}$ & $\begin{array}{l}\text { Wet } \\
\text { content }\end{array}$ & $\begin{array}{c}\text { Concentration } \\
\text { of ethanol in } \\
\text { wet } / \%\end{array}$ & $\begin{array}{c}\text { Weight lose } \\
\text { speed of material } \\
\text { /g } \text { min }^{-1}\end{array}$ \\
\hline 1 & 100 & 0.9 & 11 & 0.282 \\
\hline 2 & 100 & 0.7 & 9 & 0.235 \\
\hline 3 & 100 & 0.5 & 7 & 0.143 \\
\hline 4 & 100 & 0.5 & 5 & 0.085 \\
\hline 5 & 100 & 0.1 & 3 & 0.031 \\
\hline 6 & 80 & 0.7 & 11 & 0.165 \\
\hline 7 & 80 & 0.5 & 9 & 0.111 \\
\hline 8 & 80 & 0.5 & 7 & 0.068 \\
\hline 9 & 80 & 0.1 & 5 & 0.022 \\
\hline 10 & 80 & 0.9 & 3 & 0.212 \\
\hline 11 & 60 & 0.5 & 11 & 0.066 \\
\hline 12 & 60 & 0.5 & 9 & 0.048 \\
\hline 13 & 60 & 0.1 & 7 & 0.015 \\
\hline 14 & 60 & 0.9 & 5 & 0.12 \\
\hline 15 & 60 & 0.7 & 3 & 0.092 \\
\hline 16 & 40 & 0.5 & 11 & 0.018 \\
\hline 17 & 40 & 0.1 & 9 & 0.009 \\
\hline 18 & 40 & 0.9 & 7 & 0.063 \\
\hline 19 & 40 & 0.7 & 5 & 0.048 \\
\hline 20 & 40 & 0.5 & 3 & 0.034 \\
\hline 21 & 20 & 0.1 & 11 & 0.002 \\
\hline 22 & 20 & 0.9 & 9 & 0.015 \\
\hline 23 & 20 & 0.7 & 7 & 0.012 \\
\hline 24 & 20 & 0.5 & 5 & 0.009 \\
\hline 25 & 20 & 0.5 & 3 & 0.005 \\
\hline & & & \\
\hline & & 9 & \\
\hline
\end{tabular}

Test procedures:

(1) 25 samples of totally dried fermented material were taken which every sample weight $2 \mathrm{~g}$. One was putted into a preservation bag and added with $18 \mathrm{~g}$ ethanol solution which concentration is $11 \%$. The bag was sealed and putted in shade until there was no liquid in bag (it commonly takes 1 day). As a result, $20 \mathrm{~g}$ prepared material with wet content 0.9 and ethanol concentration $11 \%$ in wet was complete, as the first line's level in table I. The sample was marked No 1 . The other 24 bags of prepared material were prepared likewise. The volume of all prepared material were the same.

(2) The temperature of heating disc in moisture analyzer was set $100^{\circ} \mathrm{C}$, as the first line's level in table I, and the No 1 prepared material was putted on the disc. The weight data was automatically recorded until the material was totally dried. The other 24 samples was distilled likewise. The spread situation of every sample on disc were the same.

(3) Weight lose speeds were calculated based on weighttime date and filled in table I.

The range analysis shows that the factors' importance order of influence on distilling speed of material is heating temperature $>$ wet content $>$ ethanol concentration in wet, the order of magnitude of heating temperature and wet content are the same, the order of magnitude of ethanol concentration in wet is lower than the other two factors. The variance analysis shows that heating temperature and wet content is significant.

In order to regress function of weight lose speed, heating temperature and wet content, complete test need to be done. The factors' levels were shown in table II.

TABLE II. FACTORS AND LEVELS OF COMPLETE TEST

\begin{tabular}{|l|l|l|}
\hline \multicolumn{1}{|c|}{ Factors } & \multicolumn{1}{c|}{ Levels } & \multicolumn{1}{c|}{ Unit } \\
\hline Wet content & $0.9 / 0.7 / 0.5 / 0.3 / 0.1$ & 1 \\
\hline Ethanol concentration in the wet & $11 / 9 / 7 / 5 / 3$ & $\%$ \\
\hline Heating temperature & $100 / 80 / 60 / 40 / 20$ & ${ }^{\circ} \mathrm{C}$ \\
\hline
\end{tabular}

Test procedures:

(1) 125 samples of totally dried fermented material were taken which every sample weight $2 \mathrm{~g}$. Five of the samples were separately putted into 5 preservation bags with $18 \mathrm{~g}$ ethanol solution of $11 \mathrm{R} \%$. The bags were sealed and putted in shade until there was no liquid in them which means that the wet has been completely absorbed by dried material. As a result, 5 prepared material samples of $20 \mathrm{~g}$, wet content 0.9 , ethanol concentration $11 \%$ were got, and they would be distilled under $100 / 80 / 60 / 40 / 20^{\circ} \mathrm{C}$. The other 120 bags of prepared material were prepared likewise. The volume of all prepared material were the same.

(2) The 125 bags of material were orderly distilled on heating disc. The spread situation of them on disc were the same. The weight data was automatically recorded until the material was totally dried.

(3) Weight lose speeds were calculated based on weighttime date and 125 values were got. The weight loss speed under wet content 0 was set zero. 130 values were got for function regression.

(4) Heating temperature was set as $X$ axis, wet content was set as $\mathrm{Y}$ axis, weight loss speed was set as $\mathrm{Z}$ axis, 3-D surface chart under different ethanol concentration in wet were drawn, and all the surfaces were projected into cloud charts on X-Y coordinate system, as shown in figure 2.

As shown in figure 2, the influence of ethanol concentration in wet on weight loss speed is much smaller than the other two factors. As a result, under simplified treatment, the influence of ethanol concentration in wet can be ignored. As the ethanol concentration in wet of fermented material is commonly $7 \%$, the following research is based on $7 \%$.

As shown in figure 3, weight loss speed linearly increases with higher wet content, increases as power function with higher heating temperature. Regress function by SPSS software ${ }^{[13]}$, use mathematical model $v=\left(p 1+t^{p 2}\right) \cdot p^{3} \cdot x$ : 


$$
\begin{gathered}
v=\left(-42.7971236907706+t^{1.49471503671573}\right) \\
\cdot(-0.000340641906910112) \cdot x
\end{gathered}
$$

$\mathrm{V}$-weight loss speed, g/min;

$\mathrm{x}$-wet content, dimensionless;
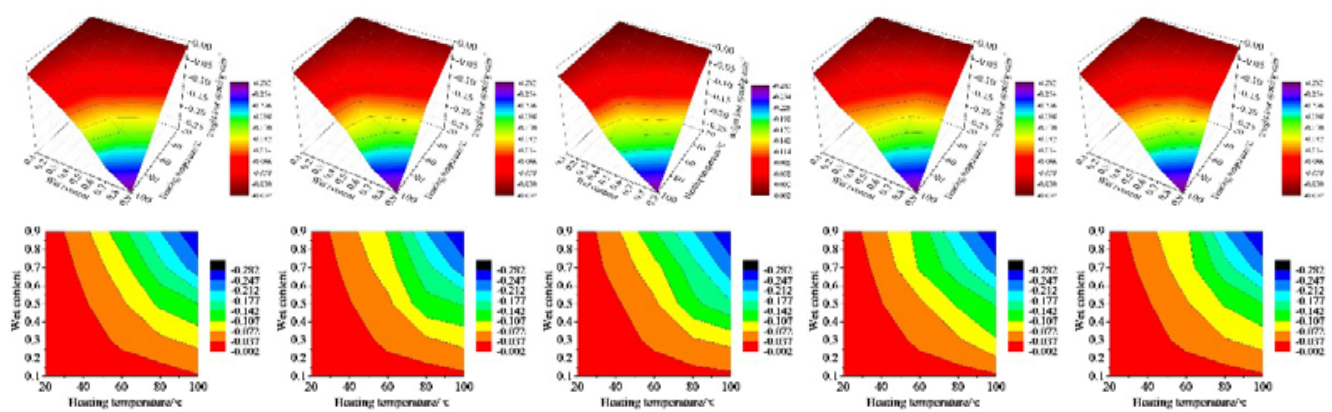

FIGURE II. WEIGHT LOSE SPEED UNDER DIFFERENT HEATING TEMPERATURE, WET CONTENT, CONCENTRATION OF ETHANOL IN THE WET (LEFT $\rightarrow$ RIGHT: ETHANOL CONCENTRATION 11\%, 9\%, 7\%, 5\%, 3\%)

TABLE III. WEIGHT LOSE SPEED UNDER ETHANOL CONCENTRATION 7\% IN WET /G·MIN ${ }^{-1}$

\begin{tabular}{|l|c|c|c|c|c|}
\hline \multirow{2}{*}{$\begin{array}{c}\text { Wet } \\
\text { content }\end{array}$} & \multicolumn{5}{|c|}{ Heating temperature $/{ }^{\circ} \mathrm{C}$} \\
\cline { 2 - 6 } & $\mathbf{2 0}$ & $\mathbf{4 0}$ & $\mathbf{6 0}$ & $\mathbf{8 0}$ & $\mathbf{1 0 0}$ \\
\hline 0.9 & -0.015 & -0.063 & -0.12 & -0.212 & -0.282 \\
\hline 0.7 & -0.012 & -0.048 & -0.092 & -0.165 & -0.235 \\
\hline 0.5 & -0.009 & -0.034 & -0.066 & -0.111 & -0.143 \\
\hline 0.3 & -0.005 & -0.018 & -0.048 & -0.068 & -0.085 \\
\hline 0.1 & -0.002 & -0.009 & -0.015 & -0.022 & -0.031 \\
\hline
\end{tabular}
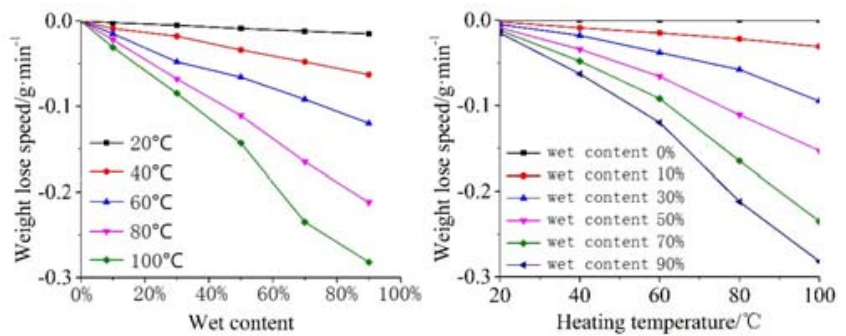

FIGURE III. WEIGHT LOSE SPEED UNDER ETHANOL CONCENTRATION 7\%

Weight lose speeds under levels of table II were calculated with function 8 . Wet content was set as $\mathrm{X}$ axis, heating temperature was set as $\mathrm{Y}$ axis, weight loss speed was set as $\mathrm{Z}$ axis, 3-D surface chart and clout chart were drawn with the calculated data.

As shown in figure 4, the difference between charts drawn by experimental date and calculated date is very small. The relative error between them is smaller than $10 \%$. The function meets engineering precision requirement.
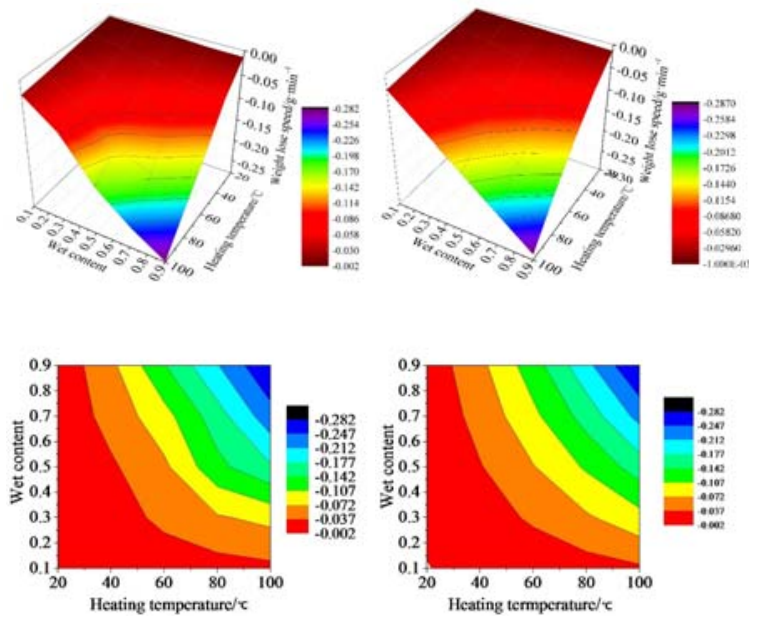

FIGURE IV. WEIGHT LOSE SPEED (LEFT: EXPERIMENTAL DATA, RIGHT: CALCULATED DATE BY FUNCTION 8)

\section{The Simulation Method on Distillation Process BASED ON DEM}

DEM is an effective method to simulate the motion, contact and heat transfer of particles ${ }^{[14]}$. With function 8 , simulation method on distillation process could be built based on DEM: single particle represents small volume material, a number of particles represent a large amount of material, the motion, heat transfer and weight loss process of material can be simulated as particles' motion, heat transfer and weight loss process. As a result, distillation process in electric heating equipment could be studied by simulation. However, there is no DEM software which can simulate the change process of particle mass, secondary development need to be done with API.

\section{A. Discrete Element Method (DEM)}

DEM was put forward in middle of 20th century and popularized in the recent 20 years with developing of computer 
technology [15]-[17]. In DEM, the discontinuous research object was separated as aggregates of particles, every particle meets the kinetic equations and heat conduction models, and the dynamic state of every particle in every moment is iterative computed. The core of DEM is kinetic equations ${ }^{[18]-[20]}$.

\section{B. Simulation Method on Distillation Process}

The electric-heating distilling process of fermented crushed straw material consists of two parts: conduction and convection. As the material layer is thin, convection can be ignored.

In DEM software EDEM, particle density is a constant. In order to simulate weight loss process, the particle density in EDEM need to be changed into a variable quantity which changes with particle temperature and time. That needs API. As the volume of material does not change during heating process, the volume of particle in EDEM does not have to change.

$$
\begin{gathered}
\rho_{\mathrm{l}+1} \cdot V=\rho_{i} \cdot V-\frac{v \cdot d \tau}{600000} \\
x=1-\frac{\rho_{i} \cdot V}{\rho_{0} \cdot V} \\
\rho_{\text {man }}=\rho_{0}\left(1-x_{0}\right) \\
\rho_{i} \geqq \rho_{\min }
\end{gathered}
$$

$\rho_{\mathrm{i}}$-density of particle, $\mathrm{kg} / \mathrm{m}^{3}$;

$\rho_{i+1}$ - density of particle which changes from $\rho_{\mathrm{i}}$ in a time step, $\mathrm{kg} / \mathrm{m}^{3}$;

$\mathrm{v}$ - volume of a particle, which is the same as small volume material, $\mathrm{m}^{3}$;

$\mathrm{d} \tau$ - time step, $\mathrm{s}$;

$v$ - weight lose speed of particle, $\mathrm{g} / \mathrm{min}$;

$\mathrm{t}$ - temperature of particle under density $\rho_{\mathrm{i}},{ }^{\circ} \mathrm{C}$;

$\mathrm{x}$ - wet content of small volume material under bulk density $\rho_{\mathrm{i}}$, dimensionless;

$\mathrm{x}_{0}$ - initial wet content of material, decimal;

$\rho_{0}$ - initial bulk density of material, measured ${ }^{[21]}, \mathrm{kg} / \mathrm{m}^{3}$;

$\rho_{\text {min }}$ — bulk density of completely dried material, $\mathrm{kg} / \mathrm{m}^{3}$.

Function (8) to (12) were programmed into EDEM with API, thus the particle density is changeable and EDEM can simulate the electric-heating distilling process of fermented crushed straw material. The simulation stops when $\rho_{i}=\rho_{\text {min }}$, which means that the particle density has decreased to the same as density of totally dried material. The distillation degree is the weight loss degree of particles. The residual mass of ethanol at any time can be calculated with VB software programmed upon function (1) to (7).
The simulation aimed at designing electric-heating distilling equipment and reducing the cost of ethanol distillation from solid-state fermented crushed straw material ${ }^{[22]}$.

\section{COMPARISON OF SimUlation AND TEST}

\section{A. Single Particle Simulation and Small Volume Material Distillation}

In EDEM, single particle's mass, density, volume and surface properties were set to the same as the $2 \mathrm{~g}$ small volume material, as a result single particle can represent the $2 \mathrm{~g}$ small volume material. The factors' levels were considered based on industrial situation: wet content $0.5 / 0.7 / 0.9$, heating temperature $60 / 80 / 100^{\circ} \mathrm{C}$. The distillation of single particle was simulated and the weight date was derived. The weight change curve was changed into wet change curve. The curves of test and simulation were compared, as shown in Figure 5, the difference between them is small.
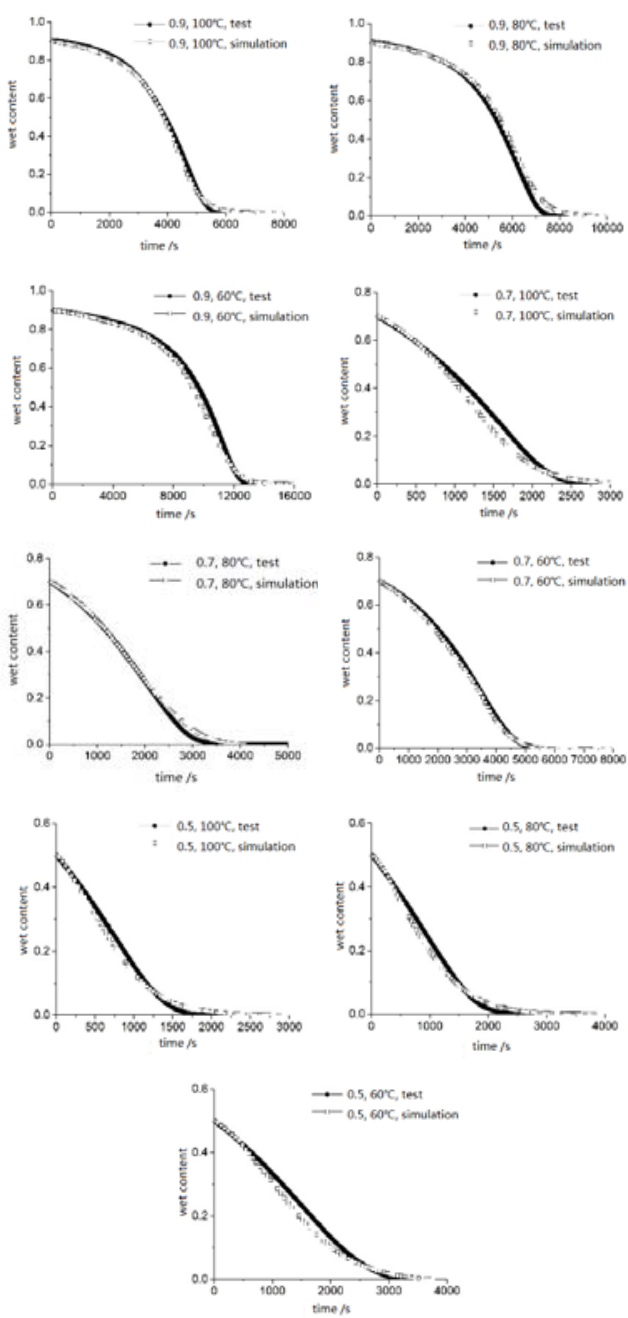

FIGURE V. SINGLE PARTICLE DISTILLATION WET CURVES OF SIMULATION AND TEST 


\section{B. Multi Particle Simulation and Material Distillation}

Every single particle's properties in EDEM was set to the same as the $2 \mathrm{~g}$ small volume material. The electric-heating distillation tank is $1 \mathrm{~m} \times 1 \mathrm{~m} \times 0.01 \mathrm{~m}$, upper opening, bottom heating, walls insulation. The mass of particles (material) was $3.4 \mathrm{~kg}$, wet content 0.7 , ethanol concentration $7 \%$ in wet, the heating temperature of tank was $100^{\circ} \mathrm{C}$. The tank distillation of material was done and weight date was automatically recorded. The tank distillation of particles was simulated in EDEM and weight date was derived. The weight curves of test and simulation were changed into wet curves and compared. As shown in figure 6 , the wet curve of simulation match with test.

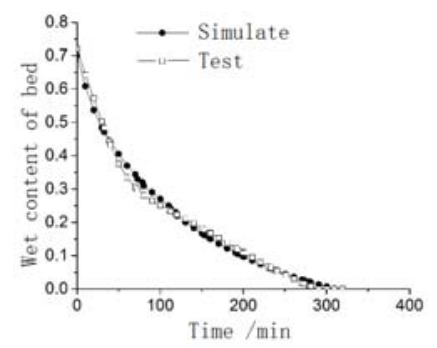

FIGURE VI. MORE PARTICLES DISTILLATION WET CURVES OF SIMULATION AND TEST

\section{CONClusion}

(1) The factors' influence order on weight loss speed of fermented material under electric-heating distilling is heating temperature $>$ wet content $>$ ethanol concentration in wet, the order of magnitude of heating temperature and wet content are the same, the order of magnitude of ethanol concentration in wet is lower than the other two factors. The influence of heating temperature and wet content are significant.

(2) Weight loss speed linearly increase with higher wet content, increase as power function with higher heating temperature. Function was regressed by SPSS software.

(3) The functions were programmed into EDEM with API and $\mathrm{C}++$, a set of simulation method focused on electricheating distillation of fermented crushed straw material was built. The simulation result match with test result. The simulation method can be used on designing and optimizing of series electric-heating distillation equipment. The research ideas can also be extended to study the problems of variable values of particles under heating.

\section{ACKNOWLEDGMENT}

The work is fully financed by the National Key Research and Development Program of China under Grant No. 2016YFB0601305, and Beijing Municipal Education Commission mutual-building Program.

\section{REFERENCES}

[1] Hui QU, Yixin SHEN, "The general research situation on sweet sorghum at home and borad," Collection of the second china grassland agriculture conference. Beijing, 2012.

[2] Bing HAN, Li WANG, Shizhong LI, Erqiang WANG, Lei ZHANG, Tiancheng LI, "Ethanol production from sweet sorghum stalks by advanced solid state fermentation (ASSF) technology," Chinese journal of biotechnology. Vol.26, pp.966-973, 2010.

[3] Shizhong LI, Guangming LI, Lei ZHANG, Zhixing ZHOU, Bing HAN, Wenhui HOU, etc, "A demonstration study of ethanol production from sweet sorghum stems with advanced solid state fermentation technology," Applied Energy, 2013, 102: 260-265.

[4] Fang LI, "Experimental study on ethanol distillation of solid-state fermented materials," Tianjin University of Science and Technology. 2011.

[5] Ruiming WANG, "The study of solid state fermentation production technology for fuel-ethanol," Tianjin University of Science and Technology, 2002.

[6] Guangteng ZHANG, Aizhen PAN, Zhenjun SI, "Research of fuel ethanol distillation new technology and equipment," Value engineering, vol.31, pp.32-33, 2012.

[7] Hongdong YAN, "Variation of stem content and fermentation study of sweet sorghum," Chinese academy of agricultural sciences dissertation, 2013.

[8] Zhengyang HU, Lu CAI, Haidong LI, Guoxuan DAI, "Determination of oil concentration in emulsion by thermo balance method," Anhui Metallurgy, vol.1, pp.46-47, 2013.

[9] Mingsong XIAO, Mengjie WANG, Fuel ethanol production technology and engineering construction, Posts \& Telecom Press, 2010.

[10] Jianguo WANG, Lijuan JIAO, Visual Basic program design, China Railway Publishing House, 2014.

[11] Jie LIU, Shimei ZHENG, Yuanyou LI, Shifan WANG, Yongli LIU, Zhanjin ZHANG, etc, "Experimental reports on ethanol production from sweet sorghum stems (I) - experiments on ethanol production from different species," Liquor-making science \& technology, vol.5, pp.51-53, 2007.

[12] Jie LIU, Zhanjin ZHANG, Bing SONG, Lixing WU, Shimei ZHENG, Yuanyou LI, etc, "Experimental Report on ethanol production from sweet sorghum stems (II) -Experiments of ethanol production by sorghum stems of different storage period," Liquor-making science \& technology, vol.9, pp.62-64, 2008.

[13] Chuanhua YU, SPSS and statistical analysis, 2nd ed., Publishing house of electronics industry, 2014.

[14] Mishra B K, "A review of computer simulation of tumbling mills by the discrete element method - Part II - Practical applications," Int. J. Miner. Process, vol.71, pp.95-112, 2003.

[15] A. B.Yu, "Discrete element method - an effective way for particle scale research of particulate matter," Eng. Comp, vol.21, pp.205-214, 2004.

[16] H.P.ZHU, Z.Y.ZHOU, R.Y.YANG, A.B.YU, "Discrete particle simulation of particulate systems: A review of major applications and findings," Chemical Engineering Science, vol.63, pp.5728-5770, 2008.

[17] Yong XU, Qicheng SUN, Ling ZHANG, Wenbin HUANG. "Advances in discrete element methods for particulate materials," Advances in mechanics, vol.33, pp.251-260, 2003.

[18] Xikui LI, Yuntian FENG, Shunying JI, Research progress of computational mechanics of granular material, Press of Dalian University of Technology, 2012.

[19] G.R. Chandratilleke, A. B. YU, Bridgwater J, "A DEM study of the mixing of particles induced by a flat blade," Chemical Engineering Science, vol.79, pp.54-74, 2012.

[20] Qicheng SUN, Guangqian WANG, An introduction to the mechanics of granular material, Science Press, 2009.

[21] Li SUN, Nongxue QIU, Physical properties and measurement of agricultural products, Chongqing Press, 2007.

[22] Xiaoyan MEI, Ronghou LIU, Weixing CAO, "Techno-economic assessment on pilot-scale plant for fuel ethanol production from sweet sorghum stem by solid state fermentation," Transactions of the CSAE, vol.27, pp.243-248, 2011. 